- RAM, REV. ADM. MACKENZIE, V. 12, N. 1 - SÃO PAULO, SP • JAN./FEV. 2011 • ISSN 1678-6971 •

Submissão: 14 dez. 2009. Aceitação: 3 nov. 2010. Sistema de avaliação: às cegas dupla (double blind review). UNIVERSIDADE PRESBITERIANA MACKENZIE. Walter Bataglia (Ed.), p. 53-81.

\title{
UMA APROXIMAÇÃO ENTRE LIDERANÇA TRANSFORMACIONAL E TEORIA DA AÇÃO COMUNICATIIVA
}

FABIO VIZEU

Doutor em Administração de Empresas pela Escola de Administração de Empresas de São Paulo da Fundação Getulio Vargas (FGV-SP). Professor do Programa de Mestrado e Doutorado em Administração da Universidade Positivo.

Rua Prof. Pedro Viriato Parigot de Souza, 5.300, Campo Comprido

Curitiba - PR - Brasil - CEP 81280-330

E-mail: fabio.vizeu@gmail.com 


\section{RESUMO}

Desde o trabalho seminal de Burns (I978) sobre liderança transformacional, muitos autores defendem que líderes são bem-sucedidos se não se comportam como gerentes. Longe de representar um argumento sem base teórica, defende-se que o modelo de liderança transformacional pode ser considerado a partir do ponto de vista de teorias sociais mais complexas como a Teoria da Ação Comunicativa, de Habermas. Essa é a proposta deste trabalho, que, considerando a dicotomia entre a ação estratégica e a ação comunicativa, observou os fundamentos ontológicos para a diferenciação entre gerentes e líderes transformacionais. Nesse sentido, reconhecemos que a Teoria da Ação Comunicativa provê análise crítica da liderança transformacional, pois permite uma melhor compreensão de alguns de seus elementos, ao mesmo tempo que questiona outros, provendo um entendimento menos ingênuo sobre o fenômeno da liderança, tal qual aquele apresentado pela visão gerencialista nos estudos da liderança. Uma dessas contribuições é a concepção da liderança transformacional como um fenômeno contextualizado pela liberdade do discurso, propiciando a ação comunicativa a partir de mecanismos organizacionais que são livres de constrangimentos à interação comunicativa, permitindo reciprocidade entre os agentes da liderança.

\section{PALAVRAS-CHAVE}

Liderança transformacional; Liderança transacional; Dicotomia líder-gerente; Ação comunicativa; Racionalidade instrumental.

\section{INTRODUÇÃO}

A crescente importância do tema da liderança na área de organizações pode ser medida pela força com que esse assunto se apresenta tanto na literatura aca- 
dêmica quanto naquela endereçada ao público executivo. Apesar de ser um objeto de estudo desde muito tempo presente nas pesquisas das áreas de recursos humanos e comportamento organizacional (BERGAMINI, I994), somente há alguns anos é que vem ganhando força a ideia de que a liderança é uma atividade distinta da gerência. Na verdade, por mais controverso que esse entendimento possa ser - tendo em conta que a ideia de que líderes não são gerentes (BENNIS, I996) é proposta justamente para os que exercem cargos de gerência -, ele reflete a crise no modelo gerencial clássico, constituído historicamente com o taylorismo (BRAVERMAN, I98I) e que é predominante no mundo corporativo até os dias atuais.

De todas as propostas recentes sobre liderança, certamente uma das mais sintonizadas com o novo contexto de descontinuidade e mudança no qual as organizações contemporâneas estão sujeitas (DRUCKER, I970) é a liderança transformacional. Baseada no estudo seminal de James McGregor Burns (I978), essa perspectiva de liderança tem sido considerada um tipo de influência que permite aos seguidores exercer um desempenho organizacional além da expectativa (BASS, I985). Desde a proposta inicial, têm sido vinculadas a esse tipo de liderança diferentes denominações para expressar sua essência - tais como liderança moral (BURNS, I978), liderança visionária (BENNIS; NANUS, I988; BASS, I990), liderança inspiracional (BASS; AVOLIO, I990) ou mesmo liderança carismática (SHAMIR, I99I); porém, o que faz dessas diferentes concepções convergentes é o fato de que todas são definidas pelo alcance e potencial do tipo de influência que se estabelece, tendo em conta que essa é considerada transformadora na medida em que os liderados são levados a emancipar-se. Nas organizações contemporâneas, a influência transformacional se exprime especialmente pela capacidade visionária em situações problemáticas e/ou desafiadoras que levam a mudanças significativas de comportamento e/ou atitude (BASS, I985; I990; BENNIS; NANUS, I988).

Entre os autores da liderança transformacional, certamente dois dos mais profícuos são Bernard Bass e Warren Bennis, o primeiro, influenciando significativamente a produção de pesquisas acadêmicas de cunho empírico, e o segundo, com uma popularidade crescente particularmente no círculo corporativo. Em relação a Bennis, que constitui uma espécie de discurso pop sobre liderança, severas críticas são feitas ao viés gerencialista presente em sua proposta, críticas essas merecidas, tendo em conta que ele se esforçou nos últimos anos em se afastar do academicismo tão demonizado pelos praticantes da gerência. Entretanto, é preciso considerar que a concepção de liderança gerencialista se contradiz em relação à concepção original de Burns (I978), porque, por um lado, se condiciona demasiadamente a tendência de instrumentalização do conhecimento a serviço da prática gerencial e, por outro, ao atendimento do interesse 
econômico que permeia essa atividade. Nesse ponto, é preciso reconhecer que a orientação exclusivamente voltada para o interesse econômico que perpassa o discurso gerencialista é, sob o ponto de vista da teoria social crítica de Habermas (I987), um dos grandes obstáculos ao estabelecimento da emancipação no contexto da modernidade, algo que deve ser considerado dentro de uma análise crítica da literatura sobre liderança.

Assim, o objetivo do presente trabalho é analisar as ideias sobre a liderança transformacional à luz das referências teóricas da ação comunicativa, a teoria de ação social do filósofo alemão Jürgen Habermas, verificando as possibilidades que essa proposta de liderança assume quando avaliada por uma teoria de cunho crítico e de orientação ontológica interpretativista. Nesse sentido, consideramos central para a aproximação proposta a dicotomia de Habermas (I987) entre a ação estratégica (orientada ao êxito) e a ação comunicativa (orientada ao entendimento intersubjetivo), que nos parece encerrar os fundamentos ontológicos para a diferenciação entre o gerente e o líder transformacional.

Nesse sentido, reconhecemos que a Teoria da Ação Comunicativa permite a análise crítica da liderança transformacional, pois permite um melhor dimensionamento de alguns de seus elementos, ao mesmo tempo que questiona outros, vislumbrando um entendimento sobre o fenômeno da liderança menos ingênuo, tal qual aquele apresentado pela visão gerencialista nos estudos da liderança. Uma dessas contribuições destacadas no presente artigo é a concepção da liderança transformacional como um fenômeno contextualizado pela liberdade de fala propícia à ação comunicativa, tal qual estudos empíricos sobre esse modelo de ação têm procurado apontar, em que os mecanismos de organização que condicionam a interação social são livres de constrangimentos à interação comunicativa plena, permitindo a reciprocidade entre os agentes da liderança.

Além de sua introdução e conclusão, o presente texto é dividido em quatro partes. Na seção seguinte, fazemos uma breve apresentação dos principais aspectos da liderança transformacional, ressaltando sua localização histórica dentro da pesquisa sobre liderança em organizações. Logo em seguida, consideramos a crítica ao perfil gerencial clássico presente na abordagem da liderança transformacional, vinculando-a com o questionamento à orientação para a eficiência predominante na área de Administração desde o taylorismo. Depois, mudamos o foco do nosso olhar para a teoria da ação comunicativa, onde apresentamos os principais elementos dessa teoria e como ela tem sido adotada nos estudos da administração e das organizações. Com os argumentos desenvolvidos até essa etapa, temos condições de tratar o principal objetivo deste trabalho, ou seja, avaliar criticamente o modelo de liderança transformacional à luz da teoria da ação comunicativa de Habermas, tecendo considerações que permitam verificar as possibilidades e os limites desse modelo. 


\section{PRESSUPOSTOS DA LIDERANÇA TRANSFORMACIONAL}

Desde a origem das abordagens sistemáticas da administração moderna existem estudos sobre os efeitos da liderança no contexto organizacional. De modo geral, os revisionistas deste campo de estudo verificam que, até a década de I970, basicamente existiram três grandes movimentos de pesquisas sobre liderança (BERGAMINI, I994), delineadas por diversos pesquisadores e especialistas do comportamento humano e organizacional: I. a abordagem dos traços, onde se enfatizavam as qualidades dos "bons líderes" (ou seja, aqueles que supostamente promoviam um melhor desempenho de seus liderados); 2. a perspectiva dos estilos de liderança, onde a preocupação dos pesquisadores residia na descoberta ou validação de determinados comportamentos de liderança, e 3. os enfoques situacionais de liderança, que contemplam os pressupostos das teorias organizacionais contingencialistas e preocupam-se em determinar a associação de determinado comportamento de liderança a um contexto específico.

Sendo posterior a esses três enfoques, a abordagem da liderança transformacional apresenta pressupostos significativamente distintos a eles. Primeiro, a preocupação das pesquisas sobre liderança transformacional é delinear um modelo específico de estilo que, mesmo sendo universal, presume-se ser particularmente adequado ao atual contexto de intensas mudanças e descontinuidades pelo qual as organizações contemporâneas estão sujeitas (DRUCKER, I970). Além disso, o modelo transformacional é centrado na suposição de que a liderança é um fenômeno dual - ou seja, se explica necessariamente pela relação entre líder e liderados, e não apenas pelo entendimento do comportamento dos líderes (BURNS, I978). Assim, a ênfase passa à delimitação dos fatores que permitem a transformação do padrão de comportamento do liderado, de maneira a permitirlhe o autodesenvolvimento, mas também, o desenvolvimento coletivo em direção a um ambiente de trabalho emancipador. É por esse motivo que a liderança transformacional tem sido considerada como um modelo pertinente ao atual contexto organizacional, tendo em vista o fato das organizações viverem intensamente em contextos turbulentos, marcados por intensa complexidade ambiental, bem como por uma crise de comprometimento de seus trabalhadores e de credibilidade das organizações perante a sociedade (BENNIS; NANUS, I988).

\subsection{O PIONEIRISIMO DE BURNS}

A perspectiva da liderança transformacional foi apresentada pela primeira vez por Burns (1978). Apesar disso, outros autores da época desenvolveram pro- 
postas muito semelhantes, o que fez que houvesse uma convergência desses estudos para uma mesma abordagem, centrada em um entendimento alternativo à visão gerencialista do contingencialismo - onde o gerente assume-se como o principal ator de análise da liderança - visão essa que predominava na década de I970.

A proposta de Burns (I978) sobre a liderança transformacional, além de ter sido a pioneira, é também considerada a de maior influência sobre outros pesquisadores dessa abordagem (BASS, I999a; DVIR et al., 2002), já que foi a partir desse texto seminal que outros importantes pesquisadores desenvolveram suas proposições (como Bernard Bass, certamente o mais profícuo no meio acadêmico). Vindo da área de ciência política, James McGregor Burns desenvolveu seu texto sobre liderança inspirando-se nos grandes líderes da história política norte-americana (BAILEY; AXELROD, 200I).

Sustentado pelas ideias de Maslow sobre a hierarquia de necessidades e de Kolberg sobre o desenvolvimento moral (BAILEY; AXELROD, 200I; DVIR et al., 2002), Burns (I978) apresenta dois modelos distintos de liderança, comuns tanto na vida política quanto na esfera privada: a liderança transacional e a liderança transformacional. A primeira consiste no estilo de liderança baseado na capacidade do líder em atender os interesses particulares dos seguidores; já o segundo estilo corresponde à liderança centrada no desenvolvimento dos seguidores, de maneira a permitir que esses adotem um comprometimento com valores coletivos substantivos.

Para Burns (I978) e seus seguidores (BASS, I999a; DVIR et al., 2002), os líderes transacionais são aqueles que enfatizam sua capacidade de influência no poder de garantir atendimento das necessidades que os seguidores apresentem, seguindo uma lógica utilitarista de recompensa e punição, ou mesmo de barganha. Nesse sentido, não há no modelo transacional uma preocupação com a coletividade ou com princípios moralmente determinados, por isso, diz-se ser um modelo que enfatiza o autointeresse (seja dos seguidores, seja do líder), em uma relação de troca orientada instrumentalmente. Além disso, Burns enfatiza que o modelo de líder transacional, por não ter uma preocupação com o desenvolvimento moral dos seguidores, geralmente atende às necessidades mais baixas da hierarquia de Maslow (fisiológicas, de segurança, sociais e de estima), que, geralmente, dizem respeito a expectativas contratuais (BASS, I985).

Já os líderes transformacionais, segundo Burns (I978), inspiram moralmente seus seguidores, e, assim fazendo, estimulam o desenvolvimento de necessidades de autorrealização e comprometimento com valores e interesses coletivos. Como sugerem Dvir et al., (2002, p. 736), “diferentemente dos líderes transacionais, que se concentram no atendimento de necessidades atuais, os 
líderes transformacionais fazem emergir necessidades latentes". Sob o ponto de vista do desenvolvimento moral, o líder transformacional leva seus seguidores a transcender seus interesses egoísticos em nome dos valores da coletividade na qual estão inseridos. Para tanto, eles utilizam competências interativas específicas, tais como a inspiração visionária, a comunicação e o "empoderamento" (BURNS, I978; BARBUTO JR., I997; DVIR et al., 2002; BASS, I985; I999a).

\subsection{A CONTRIBUIÇÃO DE BASS}

Sem sombra de dúvidas, Bernard Bass foi o mais profícuo pesquisador do modelo de liderança transformacional, particularmente sob o ponto de vista da sistematização de metodologia para pesquisa empírica e da construção conceitual necessária a tal intento. Nesse sentido, uma importante diferença entre Burns (1978) e Bass (1985; 1990) é que este último explorou diretamente as premissas apresentadas pelo primeiro no contexto das organizações produtivas. Assim, Bass tem sido mais referenciado que Burns apenas na medida em que desenvolveu um modelo mais amplo e sistemático, que permitiu o desenvolvimento de pesquisas organizacionais empíricas, pois foi baseado em inferências mais diretas sobre a relação entre a liderança e o desempenho coletivo, seja ele considerado na esfera micro (pequenas empresas e grupos), macro (grandes organizações) ou metassocial (movimentos sociais ou lideranças de Estado ou mundiais).

Metodologicamente, a grande contribuição de Bass (BASS, I985; I990; I999a; I999b; BASS; AVOLIO, I990; AVOLIO; BASS, I99I) foi ter desenvolvido o questionário multifatores de liderança (cuja sigla em inglês é MLQ), com a intenção de medir empiricamente aspectos para caracterizar a presença de traços transformacionais e transacionais, bem como a predominância de um ou outro conjunto. Conceitualmente, Bass propôs o modelo de quatro fatores da liderança transformacional, sustentando-se tanto no trabalho seminal de Burns (I978) quanto em pesquisas empíricas por ele realizadas. São eles, a influência idealizada, a inspiração, a estimulação intelectual e a consideração individualizada (BASS, I999a; AVOLIO; BASS, I99I).

O aspecto "influência idealizada" foi apresentado originalmente por Bass (I985) pela denominação "carisma", mas o termo foi substituído anos mais tarde por ele e outro coautor (AVOLIO; BASS, I99I) para precisar melhor o conceito e diferenciá-lo de entendimentos do senso comum (BASS, I999a). Segundo esse autor, essa característica da liderança transformacional representa a capacidade de influenciar seguidores por meio de um ideal (ou mesmo por ideologias e/ou valores socialmente compartilhados). É a partir desse aspecto que emerge a transcendência da orientação para os interesses egoísticos, o que, como já dissemos, é um 
condicionante fundamental para esse tipo de liderança. Para tanto, a presença da influência idealizada está associada a comportamentos coletivamente orientados (tais como o altruísmo, a esportividade, a virtude cívica, a cortesia etc.), que vão além do estágio de autorrealização do topo da hierarquia de necessidades de Maslow. Como considerou Bass (I999a, p. I2) em menção à descrição de Burns (I978), o líder transformacional é aquele que

[...] não apenas move os seguidores acima na hierarquia de necessidades de Maslow, mas também move-os para transcender seus próprios interesses particulares, presumidamente, também os de auto-realização.

A inspiração, apresentada anos após a primeira sistematização de Bass (BASS; AVOLIO, I990), é um aspecto intrinsecamente relacionado ao anterior. Como indica Bass (I999a, p. II),

[...] a influência idealizada e a inspiração são demonstradas quando o líder vislumbra um futuro desejável, articula como ele pode ser alcançado, apresenta um exemplo de como ser seguido, apresenta altos padrões de performance e demonstra determinação e confiança.

Mesmo sendo difíceis de diferenciar empiricamente (BASS, I990), é preciso especificar conceitualmente a inspiração e a influência idealizada. Assim, a inspiração é uma categoria de natureza psicológica, que atua tanto no âmbito intelectual quanto na dimensão emocional, de maneira a estimular a busca por novas referências cognitivas. O líder inspiracional (outra denominação para remarcar o aspecto da inspiração) é aquele que nos induz a buscar um esforço além do esperado, a superação de nossos próprios limites (BARBUTO JR., I997).

A terceira característica descrita por Bass é a estimulação intelectual. Diz respeito à capacidade que o líder tem de provocar a reflexão. Muito próximo da característica anterior, esse aspecto se relaciona à capacidade argumentativa para nos fazer ir além de nossa própria visão das coisas. Como sugere Barbuto Jr. (I997, p. 692), "estimulação intelectual descreve líderes encorajando empregados a abordar problemas antigos e familiarizados de novas formas". Nesse sentido, esse atributo da liderança transformacional é condizente com a capacidade de promover a inovação e a criatividade entre os seguidores (BASS, I990; AVOLIO; BASS, I99I).

O quarto aspecto, a consideração individualizada, diz respeito ao desenvolvimento e crescimento dos seguidores propriamente dito, onde o líder transfor- 
macional suporta e orienta seus seguidores, de forma individualizada (tendo em conta as particularidades de cada indivíduo), a buscarem desafios e a promoverem o autodesenvolvimento. Esse atributo pode ser identificado quando "o líder delega tarefas como oportunidades de crescimento” (BASS, I999a, p. II).

\subsection{BASS VERSUS BURNS}

Em relação à perspectiva de Burns, Bass apresenta uma postura mais comportamentalista sobre a liderança transformacional, que pretende enfatizar aspectos que possibilitem a identificação de um padrão comportamental específico. Certamente, a ênfase na elaboração de instrumentos métricos dada pela tradição acadêmica de Bass de pesquisas sobre liderança transformacional foi estimulada pelo interesse utilitarista da prática científica, comum ao conhecimento de natureza técnico-cognitivo que, nas ciências sociais, se caracteriza pela tradição positivista (HABERMAS, I975). Nas pesquisas de Bass e seus seguidores, a instrumentalização da proposição de Burns se deu de maneira a permitir às organizações adotarem programas de seleção e desenvolvimento de líderes. Entretanto, tal intento acabou provocando distorções perigosas, que contradizem fundamentos importantes lançados pelo idealizador da perspectiva, James McGregor Burns.

A principal distorção da tradição de Bass em relação à proposta original de Burns é a adoção de uma visão reducionista do conceito de liderança transformacional. Como já sinalizamos, Burns (I978) identifica esse fenômeno como uma relação dual e uma prática coletivamente situada. Mesmo considerando o importante papel do líder na construção da liderança transformacional, Burns (I978) enfatiza o processo antes como uma construção coletiva do que individual, em que o líder é aquele que assume o papel de facilitador da emancipação dos liderados, a partir da interação centrada em uma visão coletiva baseada em valores compartilhados. Assim, para Burns, o líder transformacional se contrapõe ao transacional justamente porque atua favorecendo a perspectiva substantiva do grupo (o que se denominou como "visão"), sem perder de vista a autonomia do indivíduo enquanto tal.

Por outro lado, as condições para o estabelecimento da liderança transformacional se constituem também pela participação do grupo, que irá, por sua vez, assumir uma postura psicológica diferente daquela impressa na relação transacional. Assim sendo, a ideia por trás da concepção de Burns (I978) sobre "transformação" é a ainda basilar questão da ciência política, ou seja, a possibilidade da emancipação do sujeito dentro de um contexto socialmente determinado; em suma, a possibilidade da vida política defendida pelos filósofos gregos. É por esse 
motivo que Burns (1978) recorre à teoria do desenvolvimento moral de Kolberg para situar a referência psicológica presente na liderança transformacional: a interação social é permeada pela postura psicológica pós-convencional, na qual os agentes da liderança transformacional (líder e liderados) assumem valores que, para eles, são referências existenciais a orientar sua autopercepção de virtude, que, em suma, é a concepção aristotélica de ética (HABERMAS, I989b). Não é por acaso que Burns (I978) se inspira nos grandes estadistas que, envolvidos em contextos de liderança que afloraram em momentos históricos graves, conduziram seu próprio grupo de referência na defesa de seus valores fundamentais, aqueles que representavam base cultural de sua própria sociedade.

Nesse sentido, a identificação dos atributos do líder transformacional (proposta por Bass (I985; I990) e Avolio e Bass (I99I)) é relevante apenas no sentido de indicar uma postura que é favorável a um contexto emancipador. Por outro lado, o comportamento caracterizado na liderança transacional também sugere outro contexto, centrado na troca utilitarista e onde os valores substantivos de grupo não são considerados na ação coletiva. No comportamento transacional, a fonte de coordenação do esforço coletivo é artificialmente criada pelo líder, através do atendimento de interesses pragmáticos dos indivíduos. Tendo em conta especificamente as organizações produtivas modernas, a postura transacional parece ser a referência predominante, dada principalmente pela perspectiva do gestor como um ator racional. Na verdade, essa perspectiva sobre a prática gerencial é historicamente determinada pela postura clássica da gerência, e a contraposição à lógica transacional feita por Burns (I978) através do modelo de liderança transformacional representa, em última instância, a crítica ao perfil clássico de gerente, ou de forma mais específica, ao advento da prática administrativa e organização social moderna.

\section{A CRÍTICA AO PERFIL CLÁSSICO do GERENTE}

Especialmente no modelo de líder transformacional investigado por Bass (1985; I990) existe a contraposição ao perfil clássico de gerente (surpreendentemente, isso também é intencionado pela proposta gerencialista de Bennis e Nanus (I988)). Isso se deve ao fato de esse autor ter buscado identificar líderes que tivessem um bom desempenho dentro do contexto atual, que, pelo seu caráter peculiar de complexidade, tem desafiado as organizações. Assim, para Bass, o líder transformacional é um perfil cada vez mais importante para as organizações contemporâneas, tendo em conta que o autor defende ser esse líder capaz 
de contribuir para a integração entre os interesses da organização e os interesses individuais dos sujeitos que nela trabalham (BASS, I985), sem deixar de considerar o atual paradoxo nas relações de trabalho e a crescente necessidade por ajuste dos objetivos organizacionais às demandas sociais resgatadas pelos movimentos articulados na sociedade civil (democracia, ambientalismo, direitos humanos, direitos de minorias etc.). Na verdade, o entendimento de que, no atual momento histórico, mais do que nunca "precisamos de líderes" (BENNIS, I996, p. 22) advém da aguda crise de efetividade do perfil clássico de gerência. De certo modo, a compreensão das bases desse perfil nos permite vislumbrar o potencial da perspectiva teórica original da liderança transformadora.

O perfil clássico de gerência foi constituído pelos pressupostos da racionalização do trabalho que se estabeleceu na modernidade, na qual encontrou na doutrina da Administração Científica sua mais célebre sistematização (CHANDLER, I977; BRAVERMAN, I98I). Proposta por Frederick Taylor no início do século XX no intuito de otimizar a eficiência produtiva das organizações industriais norte-americanas, essa doutrina definiu princípios de gerência que levaram a uma intensa sistematização e padronização do trabalho em todo o mundo industrializado. Em essência, o sistema administrativo clássico consiste na padronização de sistemas produtivos, na formalização burocrática e na separação entre os agentes que pensam no trabalho daqueles que o executam (BRAVERMAN, I98I). Para a época, isso foi considerado um importante avanço, tendo em vista que foi graças a esse modelo que se consolidou nos Estados Unidos uma nova forma de capitalismo, centrada na busca pelo controle sistemático da produtividade e do próprio sistema econômico do qual as organizações fazem parte (CHANDLER, I977). Todavia, com as transformações sociais, políticas e tecnológicas, e a consequente equiparação produtiva das organizações no mundo inteiro, o modelo clássico de administração tornou-se inadequado para o enfrentamento do novo cenário competitivo que emergiu após a Segunda Guerra Mundial.

Peter Drucker foi um dos primeiros autores da administração a apontar os problemas da orientação para a eficiência do modelo clássico de gerência. Apresentando o conceito de eficácia, Drucker sinalizou sua preocupação com a perspectiva clássica da administração, especialmente diante do contexto organizacional pós-guerra, momento em que a ambiguidade e os efeitos do pensamento sistêmico se fizeram mais sentidos. O ponto central na proposição de Drucker é a necessidade de que os gestores, antes de serem eficientes no cumprimento dos modos preestabelecidos de trabalho, questionem esses modos. Além disso, ele defende que os subordinados também devem adotar essa postura reflexiva e proativa, e que é papel dos dirigentes garantir condições para que isso aconteça. A esse processo foi incorporada a ideia de que a organização deve atuar em 
ampla sinergia com o contexto social em que está inserida, pois, assim, viabiliza sua existência. Desse entendimento emergem as especulações de Drucker sobre temas mais amplos e de interesse da sociedade como um todo, tais como a responsabilidade social da empresa, o meio ambiente, a cidadania e os direitos civis (DRUCKER, I990).

Tendo em conta os pontos discutidos na seção anterior, podemos supor que o modelo clássico de administração se contrapõe à liderança transformacional. Nesse sentido, Bass (1985; I999a) associa a gerência clássica à liderança transacional, e sugere que a adoção desse estilo de liderança está em parte vinculada às condições estruturais da organização formal. Dessas condições, podemos citar como centrais a tendência à racionalização instrumental presente na estruturação burocrática que se constitui a partir dos princípios prescritos pelos autores clássicos, em que a previsibilidade, a padronização, a intensa especialização e divisão de tarefas são alguns de seus pontos mais evidentes. Nessa forma de gestão, os mecanismos de coordenação e comando são transacionais, pois se pressupõe a adoção de uma postura utilitarista, seja por parte dos gestores, seja por parte dos trabalhadores. Mesmo que essa racionalidade de cunho instrumental se configure com algo benéfico sob o ponto de vista do funcionamento organizativo eficiente (WEBER, I974), o mesmo não acontece quando consideramos aspectos ético-morais que também são necessários para a boa manutenção da vida organizacional.

A racionalidade é um pressuposto fundamental da própria concepção de administração enquanto prática sistemática e cientificamente legitimada. É a partir da racionalidade instrumental que se encontra a base de legitimação da autoridade formal, que Weber (I974) identificou em seu modelo ideal-típico da burocracia. Em outras palavras, a submissão à autoridade legal é suportada por uma legitimação de natureza racional. Todavia, essa legitimidade ocorre em bases racionalmente estabelecidas somente no sentido técnico, o que não garante o atendimento das questões substantivas, tendo em vista que a racionalidade administrativa é aquela que visa o cálculo utilitário de consequências, sem consideração à licitude das ações pensadas a partir dessa orientação. É por isso que muitos autores identificam a racionalidade da administração moderna como algo vazio de conteúdo ético, sendo esse o principal problema para estabelecer, a partir dessa prática, um contexto social emancipatório e justo (GARCIA, I980; RAMOS, I989; SERVA, I997; VIZEU, 2005; 2004; VIZEU; BIN, 2008; ALVESSON; DEETZ, I999; FORESTER, I994).

Uma das formas de superação desse caráter contraditório da racionalidade do modelo clássico de administração (que é reflexo da lógica racional predominante na modernidade) é a busca por novas referências epistemológicas para 
a administração, que permitam a construção de uma realidade organizacional mais equânime (GARCIA, I980; RAMOS, I989). Uma das propostas que vem ganhando força é a construção de uma gestão social, baseada em racionalidades alternativas à instrumental (VIZEU, 2005). Dos teóricos críticos à racionalidade instrumental, um dos mais importantes da atualidade é Jürgen Habermas, que propõe a racionalidade comunicativa, uma referência de cunho emancipatório que atende aos pressupostos ético-morais ausentes na racionalidade instrumental (ARAGÃO, I997). Por conseguinte, a racionalidade comunicativa representa uma interessante medida para a administração, especialmente se assumida como uma orientação para a ação dos gestores (FORESTER, I994; VIZEU, 2005; ALVESSON; DEETZ, I999). Por isso, propõe-se essa modalidade como uma interessante referência teórica para se pensar nas potencialidades da liderança transformacional.

\section{OS ELEMENTOS DA TEORIA DA AÇÃO COMUNICATIVA}

A Teoria da Ação Comunicativa (TAC) é uma teoria social que se fundamenta na centralidade da comunicação enquanto processo de significação do real e de articulação do social (ARAGÃO, 1997). Dito de outra forma, a TAC parte do pressuposto de que a realidade humana é apreendida pela competência linguística, seja em sua natureza objetiva (o mundo concreto dos fatos), subjetiva (o mundo interior, ou a subjetividade), seja mesmo normativa (o mundo das normas sociais). Além disso, é pela comunicação que articulamos nosso entendimento sobre a realidade com aqueles com quem necessitamos viver juntos. Para definir esse processo, Habermas (I987) recupera da fenomenologia o termo "intersubjetividade", o qual pressupõe que, no âmbito das relações sociais, é pelo alinhamento das percepções subjetivas que se constitui objetivamente a ação coletiva e, consequentemente, a possibilidade do social.

A racionalidade comunicativa consiste de uma ressignificação do atributo racional intentada por Habermas (1987; 1989a). Para esse autor, tendo em conta a pluralidade ontológica da natureza humana - o que significa dizer que, para o ser humano, a realidade se constitui em diferentes esferas de mundo, uma objetiva, uma subjetiva e outra normativa (esta última determinada pela noção de legitimidade) -, algo somente poderia ser considerado racional se fizesse sentido em todas essas três dimensões ontológicas. Ou seja, uma ação racional seria aquela que, para todos os sujeitos implicados, fizesse sentido sob a perspectiva dos fatos (ontologia objetiva), dos sentimentos (ontologia subjetiva) e da retidão e legitimidade social (ontologia normativa), destacando-se nesta última a dimen- 
são moral. Além dessas três esferas ontológicas, Habermas (1987) considera a necessidade de que as relações mediadas comunicativamente também sejam inteligíveis, sob pena de corromper o sentido e, consequentemente, o entendimento. Para isso, Habermas identifica na filosofia da linguagem de cunho analítico os pressupostos de validade do ato de fala, onde se encontra o fundamento da racionalidade comunicativa. Esses são exemplificados no Quadro I.

\section{QUADRO I}

PRETENSÖES DE VALIDEZ DO ATO DE FALA

\begin{tabular}{|c|c|c|}
\hline $\begin{array}{l}\text { REQUISITO DE VALIDEZ } \\
\text { DO ATO DE FALA }\end{array}$ & POSSIBILIDADE DE QUESTIONAMENTO & EXEMPLOS \\
\hline $\begin{array}{l}\text { Verdade (mundo } \\
\text { objetivo) }\end{array}$ & $\begin{array}{l}\text { O que está sendo dito é } \\
\text { verdadeiro? }\end{array}$ & $\begin{array}{l}\text { "Estamos passando por } \\
\text { problemas financeiros e temos } \\
\text { que demitir." }\end{array}$ \\
\hline $\begin{array}{l}\text { Sinceridade (mundo } \\
\text { subjetivo) }\end{array}$ & O que está sendo dito é sincero? & $\begin{array}{l}\text { "Estou preocupado com a } \\
\text { situação de vocês..." }\end{array}$ \\
\hline $\begin{array}{l}\text { Retidão (mundo } \\
\text { normativo) }\end{array}$ & $\begin{array}{l}\text { O que está sendo dito é legítimo } \\
\text { ou moralmente válido? }\end{array}$ & $\begin{array}{l}\text { "Entretanto, iremos fazer as } \\
\text { demissões da maneira mais } \\
\text { justa possível e dentro da lei." }\end{array}$ \\
\hline Inteligibilidade & $\begin{array}{l}\text { O que está sendo dito é } \\
\text { inteligível? }\end{array}$ & $\begin{array}{l}\text { "Todo entenderam bem os } \\
\text { termos?" }\end{array}$ \\
\hline
\end{tabular}

Fonte: Elaborado pelo autor, adaptado de Habermas (I987; I989a).

Para Habermas (1987), tendo em conta o mundo social ser mediado por diferentes esferas ontológicas (objetiva, subjetiva e normativa), a racionalidade da ação humana deve ser capaz de contemplar justificativas nessas diferentes esferas, sob pena de se configurar racionalidades limitadas ou restritas. Para esse autor, esse é o problema da racionalidade instrumental ser referência para a ação social; o cálculo utilitário de consequências é uma orientação racional apenas no sentido ontológico objetivo. Se considerarmos, por exemplo, questões morais, as decisões racionais-instrumentais - por desconsiderarem em sua lógica interna os valores - deixam de fazer sentido (logo, deixam de ser racionais). Assim, para agirmos em conjunto com outras pessoas e de forma livre (ou seja, por vontade própria), precisamos considerar a ação como sendo plenamente racional, o que significa dizer que ela precisa fazer sentido para nós - eu e o outro - em todas as esferas ontológicas que condicionam nossas vidas. Essa é, de acordo com Habermas, a essência da vida social emancipada. 
Para serem possíveis ações sociais orientadas pela racionalidade comunicativa, Habermas (1987; 1989a) indica que os sujeitos envolvidos na articulação da ação precisam negociar argumentativamente, o que implica que eles estabeleçam uma interação comunicativa livre de constrangimentos e orientada para o entendimento intersubjetivo. Para que os critérios de racionalidade sejam contemplados, os argumentos expressos devem representar aquilo que os interlocutores realmente entendem como verdadeiro (pretensão de validade objetiva), sentem sinceramente (pretensão de validade subjetiva) e acreditam ser os valores e princípios de retidão legitimados em sua sociedade (pretensão de validade normativa) e serem inteligíveis (pretensão de inteligibilidade). A interação humana orientada para o entendimento é a verdadeira relação dialógica, e é denominada por Habermas como a ação comunicativa. Para Habermas, é somente pela ação comunicativa que é possível conciliar um acordo entre sujeitos livres, pois é nessa categoria que reside a argumentação livre e a significação intersubjetiva, onde se consideram aspectos de verdade, de sinceridade de retidão e de inteligibilidade. Como sugere o autor:

A meta do entendimento [na ação comunicativa] é a produção de um acordo, que reside na comunidade intersubjetiva da compreensão mútua, do saber compartilhado, da confiança recíproca e da concordância de uns e outros. O acordo descansa sobre a base do reconhecimento das quatro correspondentes pretensões de validez: inteligibilidade, verdade, sinceridade e retidão (HABERMAS, I989a, p. 30I).

Por outro lado, Habermas indica que a predominância em nosso período histórico de uma concepção de racionalidade instrumental, ou seja, baseada no calculo utilitário de consequências, faz que as relações sociais tenham um caráter monológico, onde o sujeito envolvido na ação, em nome do êxito pessoal, usa de argumentos na relação com seu interlocutor que, sob o estrito sentido da ontologia humana, não são válidos. É assim que, no mundo moderno, vemos pessoas manipulando o sentido da verdade dos fatos, da sinceridade nas manifestações e expressões pessoais de sentimento, das justificações morais de seus atos e da inteligibilidade do que é dito - tudo em nome do êxito pessoal na ação. Esse comportamento, apesar de ser considerado racional sob o ponto de vista da lógica instrumental, não o é sob o critério comunicativo. Denominada por ação estratégica, a manipulação dos sentidos estabelecida em nossa sociedade nas relações monológicas é fruto da orientação para o êxito, onde o critério da intersubjetividade na interação humana é suplantado pelo critério da racionalidade instrumental. Essa manipulação de sentidos é denominada por Habermas 
(I987) como comunicação sistematicamente distorcida e reflete um dos mais contundentes mecanismos de alienação do período atual.

Em síntese, Habermas enquadra teoricamente as contradições da modernidade através da contraposição entre o agir estratégico - que corresponde a um tipo de agir socialmente contraditório, onde a orientação racional é limitada por se referir a uma única esfera ontológica (a objetiva) e o agir comunicativo. Esse permeado por todas as pretensões de validade racional, ou seja, a verdade, a sinceridade, a retidão e a inteligibilidade. Por outro lado, é nesta última categoria que, segundo o autor, se pode vislumbrar a possibilidade de emancipação social, pois nela encontramos a referência psicológica da comunidade linguística. Assim se expressa o autor:

Eu abordei o agir comunicativo e o estratégico como duas variantes da interação mediada pela linguagem. No entanto, somente ao agir comunicativo é aplicável o princípio segundo o qual as limitações estruturais de uma linguagem compartilhada intersubjetivamente levam os atores - no sentido de uma necessidade transcendental tênue - a abandonar o egocentrismo de uma orientação pautada pelo fim racional de seu próprio sucesso e a se submeter aos critérios públicos da racionalidade do entendimento (HABERMAS, I990, p. 82-83).

Como saída para o problema da distorção comunicativa, Habermas aponta a construção de contextos sociais que favoreçam a comunicação plena. Esses contextos se constituem pela recuperação da interação face a face que se estabelece no mundo vivido (ARAGÃO, I997), onde não se usam mecanismos sistêmicos de mediação da interação humana que são contaminados pela lógica da racionalidade instrumental (o sistema burocrático e o sistema de regulação monetária da economia capitalista).

Em relação à ação comunicativa como referência teórica para a administração, observamos que os estudos que pretendem avaliar a realidade organizacional à luz da TAC estão sendo cada vez mais frequentes. No Brasil, esses estudos estão associados aos esforços de continuidade da proposta de Ramos (I989) sobre uma teoria substantiva da realidade organizacional. De modo geral, tais pesquisas têm procurado revelar as condições favoráveis e/ou desfavoráveis para o estabelecimento da ação comunicativa, bem como os efeitos de modelos de gestão baseados nessa nova referência para a emancipação dos sujeitos e para o estabelecimento de uma ação organizacional moralmente condicionada (SERVA, I997; FRAGA, 2000; VIZEU, 2004).

Conceitualmente, a ação comunicativa tem sido explorada como uma referência de questionamento dos pressupostos do modelo gerencial clássico 
(ALVESSON; DEETZ, I999). Considerando as pressões para o resultado econômico e a preponderância de uma lógica desumanizante expressa no modelo burocrático (WEBER, I974), a gestão clássica privilegia uma relação monológica entre o gerente e o subordinado, ou seja, uma relação comunicativa orientada para o êxito, onde, sob o ponto de vista da comunicação, o interlocutor se configura como o meio para se atingir o resultado pragmático (VIZEU, 2005). Alguns autores têm proposto que essa condição se deve à relação desigual entre gerentes e subordinados, constituída pela prerrogativa de hierarquia formal do modelo burocrático. É assim que o sistema administrativo burocrático é observado como um dos importantes fatores inibidores da ação comunicativa nas organizações (VIZEU, 2005; FORESTER, I994). Por conseguinte, a comunicação é sistematicamente distorcida nas organizações devido à falta de reciprocidade entre gerentes e subordinados, o que, por sua vez, é uma condição preexistente à interação face a face que ambos estabelecem em seu contexto vivido (FELTS, I992).

Estudos empíricos fundamentados na TAC têm comprovado essas premissas. Por exemplo, Vizeu (2004) identificou na organização pesquisada que a ação comunicativa estava associada a um modelo de gestão baseado fortemente na identidade dos membros da organização em torno de valores morais. Além disso, essa pesquisa revelou que a articulação de espaços de fala livres de constrangimento (como aquele posto pela diferenciação hierárquica) também foi importante para a possibilidade de uma orientação racional-comunicativa naquela organização. Isso confirma a ideia de que a reciprocidade entre o gestor e o subordinado é um fator importante nesse modelo organizacional. Em outro estudo, esse autor verificou que foi justamente a falta de reciprocidade que impediu a comunicação orientada para o entendimento em um contexto onde vários outros fatores estruturais favoráveis estavam presentes (VIZEU; BIN, 2008). A reciprocidade também foi verificada no estudo de Serva (I997) sobre organizações substantivas. Outros fatores identificados como importantes para a ação comunicativa foram a informalidade e a reflexividade entre os membros da organização (VIZEU, 2004; SERVA, 1997).

Apesar desses entendimentos promissores, um ponto que é pouco explorado nos estudos sobre ação comunicativa nas organizações é qual seriam as especificidades da liderança para que esse tipo de orientação se estabeleça. Isso parece ser devido ao entendimento de que a racionalidade comunicativa é algo coletivamente constituído, pressuposto esse que minimiza o papel do líder nesse processo de construção. Aqui, retornamos a questão da liderança, discutindo em que medida a TAC é uma referência proveitosa para o entendimento teórico do fenômeno da liderança nas organizações, e vice-versa. 


\section{A LIDERANÇA TRANSFORMACIONAL E A AÇÃO COḾUNICATIVA}

O ponto de partida para se avaliar o modelo de liderança transformacional a partir das premissas da TAC é considerar que, sendo esse tipo de liderança uma relação de influência orientada por valores socialmente compartilhados, o líder atua como um importante agente promotor de espaços de fala livres de distorção comunicativa. Nesse sentido, dois fatores da liderança transformacional são essenciais para essa possibilidade: o foco no desenvolvimento reflexivo dos liderados e a conduta fortemente determinada pela moral.

\subsection{O ESTÍMULO DA REFLEXIVIDADE E DA POSTURA PóS- CONVENCIONAL}

Como vimos, o líder transformacional promove a reflexividade entre os membros da organização, seja porque eles próprios assumem essa postura, seja porque "os seguidores são apoiados (por ele) para questionar seus próprios valores, crenças e expectativas, e aqueles do líder e da organização, que podem ser desatualizados ou inapropriados para problemas correntes" (BARBUTO JR., I997). Os estudos empíricos que exploram a TAC nas organizações formais apontam para a importância dessa atitude reflexiva entre os membros da organização e sua relevância para viabilizar a ação comunicativa nesses contextos sociais (VIZEU, 2004; SERVA, I997). Os indicadores da liderança transformacional apresentados por Burns (I978) e por Bass (I985; I990) e seus colaboradores, quando observadas em seu conjunto, representam um estímulo importante para a reflexividade, pois induzem ao compromisso com a coletividade. O ideal compartilhado também representa um fator importante, já que é a partir desse que a visão de grupo é constituída coletivamente de forma livre, tendo em conta que não é imposta aos indivíduos, mas é assumida por eles como algo desejável, em substituição à ação centrada nos interesses egoísticos.

$\mathrm{Na}$ perspectiva habermasiana, o atendimento dos interesses individuais em detrimento da visão de grupo é representado pela comunicação orientada ao êxito que se estabelece na ação estratégica. Nesta, membros de um mesmo grupo se posicionam como agentes de uma disputa, onde cada um considera o outro um obstáculo a ser vencido. O recurso à negociação transacional - o modelo de influência oposta à liderança transformacional - é um mecanismo de influência teleológica, onde a barganha para atender interesses individuais ocorre sem consideração a valores ou objetivos socialmente legítimos e moralmente desejados, o que, na perspectiva da teoria de Kolberg sobre desenvolvimento moral, indica 
um estágio psicológico pré-convencional. Esse estado psicológico foi sinalizado por Habermas (i989b) como o determinante de uma interação social que é antes permeada por pragmatismo do que por orientação ética e moral. Também para Burns (I978) - que, similarmente a Habermas, utiliza a teoria de Kolberg sobre desenvolvimento moral -, a liderança transformacional é suportada pela orientação pós-convencional, onde a orientação da ação se dá livre de pragmatismo, pois os atores já internalizaram os valores e as orientações morais como um valor a ser perseguido por si mesmo.

Todavia, para Burns (I978), um dos papéis centrais do líder transformacional é atuar de forma que o grupo se sinta estimulado a adotar a perspectiva pósconvencional. É por isso que Bass identifica o líder transformacional a partir de características como "inspiração", "estimulação" e "consideração". Na verdade, antes de ser alguém que determina o que o grupo irá fazer, o líder transformacional é aquele que inspira o grupo a assumir uma atitude reflexiva, a reconhecer-se como grupo e a perseguir os seus próprios valores existenciais. É por isso que os casos de liderança que serviram de inspiração para Burns (I978) foram os grandes estadistas norte-americanos que se notabilizaram por uma grande causa baseada em princípios e valores existenciais. Como Abraham Lincoln, que se notabilizou como defensor do direito universal à liberdade e da abolição da escravidão. De acordo com Burns (I978), a mobilização que o líder transformacional obtém de seu grupo é antes fruto de um comprometimento desse com uma causa compartilhada pelo grupo do que da influência pessoal tradicionalmente associada à figura do líder.

Esse é o motivo para o afastamento do termo "carisma" da literatura da liderança transformacional, já que o carisma é um atributo de influência pessoal, que não precisa necessariamente refletir o compartilhar de valores (BARBUTO JR., I997). Tendo em conta que, no sentido original cunhado por Weber (I974), carisma é uma fonte de influência baseada na diferenciação entre o líder e o seguidor, em que o líder carismático é detentor de um dom de natureza divina (o carisma). É nessa "mágica pessoal" que reside a fonte do poder de influência. Dito de oura forma, quando há essa diferenciação, não é possível o questionamento da vontade do líder, o que descaracterizaria um pressuposto essencial na relação comunicativa plena. Como afirma Barbuto Jr. (I997, p. 693), "líderes carismáticos tendem a manter os seguidores fracos e dependentes, a partir da lealdade pessoal e da obediência inquestionável", fato que compromete o princípio da reciprocidade na interação intersubjetiva.

Assim sendo, o líder transformacional é aquele que inspira através do ideal, sendo esse a representação simbólica de um sistema moral articulado comunicativamente pelo grupo e no qual se estabelece a coordenação da ação coletiva. Nesses termos, a ação moralmente situada presente na liderança transformacional é a 
mesma orientação substantiva da ação comunicativa, que busca o entendimento intersubjetivo pelo ajuste das referências ético-morais que o grupo compartilha. Quando não há esse ajuste, não é possível a coordenação coletiva da ação; quando a comunicação não é livre de distorção ou de constrangimentos linguísticos, significa que o líder não assume a "consideração individualizada" do liderado (AVOLIO; BASS, I99I), e este último se constitui meramente como um recurso para a obtenção do êxito pragmático (HABERMAS, I989b).

Outro ponto importante a ser considerado na avaliação do modelo de liderança transformacional à luz da TAC é a dicotomia "ação estratégica" e "ação comunicativa” proposta por Habermas, que pode ser associada respectivamente às dicotomias entre "gerente e líder" (BENNIS; NANUS, I988; BENNIS, I996), ou entre "líder transacional e líder transformacional" (BURNS, I978; BASS, I985). Assim, assumimos a partir da TAC que o líder transformacional adota uma racionalidade alternativa àquela que permeia a lógica da própria área de administração clássica (que é a racionalidade instrumental, voltada para a eficiência organizativa e para o êxito pessoal no ato de gerenciamento (RAMOS, I989)). Ou seja, para que se estabeleça a liderança transformacional, é necessário antes negar as premissas da racionalidade administrativa, referências essas fortemente presentes nas organizações em que atuamos (também podemos dizer, dentro da sociedade em que vivemos).

Por sua vez, a racionalidade comunicativa, sendo suportada pela ideia de intersubjetividade, é uma referência conceitual importante para a compreensão do papel do líder enquanto um articulador do ajuste livre dos sentidos assumidos pelo grupo. Para tanto, o líder transformacional adota uma postura aberta à autorreflexividade, o que pressupõe estar aberto ao questionamento de seus próprios conceitos, na mesma medida em que os seguidores são estimulados a se portar. Aceitar o argumento do outro e chegar a um consenso que norteará a ação conjunta é uma postura que deve ser assumida pelo líder e pelos liderados, mas o primeiro assume o papel de estimular esse estado de espírito, seja pelo exemplo, seja pela construção de um contexto favorável ao diálogo e a reflexão livres. Por isso, para ser coerente, os estudos sobre a liderança transformacional devem se afastar da ideia de que o líder molda a mente dos seguidores, algo que parece estar presente nos estudos de Bennis e Nanus (I988). Na verdade, tendo em conta a TAC, o líder exerce de seu "poder" de influência antes por sua habilidade de promover a liberdade de expressão, pelo reconhecimento do outro e dos valores existenciais compartilhados pelo grupo e, especialmente, incentivando os outros membros do grupo para que também assumam uma postura reflexiva. Somente assim podemos aceitar que o grande papel do líder transformacional seja o de promover a emancipação dos seguidores, tal qual se propõe com a qualificação desse tipo de liderança. 


\subsection{CRÍTICA À VISÃO COMPORTAMENTALISTA DA LIDERANÇA TRANSFORMACIONAL}

Dado o fato de que, sob a perspectiva da ação comunicativa, as relações interpessoais realmente livres são aquelas mediadas pela construção do entendimento intersubjetivo, a perspectiva comportamentalista dos autores e pesquisadores da liderança transformacional vinculados ao discurso gerencialista se apresenta significativamente divergente quando confrontada com a TAC. Os limites dessa perspectiva residem especialmente na tentativa de revigorar a visão de um líder herói e onipotente, que representa a única fonte de sucesso da liderança. Em grande parte, isso é culpa da orientação dada aos estudos dessa abordagem, que priorizam o levantamento de "traços" do líder transformacional (especialmente a corrente de Bass e seus seguidores), algo perigoso quando instrumentalizado para atender aos interesses das grandes corporações, que, diante dessa possibilidade, desejam construir mecanismos e ferramentas objetivas para a seleção de "super" líderes, tal qual foi pretendido pelos estudos de liderança que predominaram no início do século XX (BERGAMINI, I994).

Ao priorizar as competências distintivas do líder transformacional - como fizeram Bennis e Nanus (I988) -, a vertente de liderança transformacional comportamentalista exulta a assimetria entre líderes e liderados, e nega, assim, a postura psicológica de reciprocidade. Como consequência, esses autores contrariam a ideia original de Burns (I978) de que a liderança é um fenômeno constituído pelo fluxo de poder entre líder e liderados, que assumem conjuntamente a responsabilidade de constituir o ambiente emancipatório, no qual se estimula o engajamento diante de valores compartilhados. Assim sendo, ao colocar a liderança transformacional sob o crivo da TAC, defendemos o abandono das concepções gerencialistas, que visam instrumentalizar estrategicamente o modelo, especialmente enfatizando a adoção desse tipo de liderança nas funções gerenciais.

Em contraposição a esse entendimento, não somente ressaltamos que a liderança transformacional é amplamente adotada por aqueles que não exercem cargos gerenciais formais, mas também consideramos que, quanto mais essa se situa nas relações informais e não legitimadas por mecanismos de poder formalmente instituídos, mas facilmente ela se estabelecerá. Assim, destacamos que a liderança transformacional também é exercida pelos trabalhadores, algo que parece ser omitido pela literatura gerencialista. Nesse sentido, as relações informais (comunicação informal, organização informal etc.) são aspectos que devem ser mais bem tratados pelos estudiosos e pesquisas empíricas. 


\subsection{EVIDÊNCIAS EMPÍRICAS}

Para melhor situar nossa proposição de que a liderança transformacional pode ser mais bem compreendida sob o registro da ação comunicativa, consideramos nesta sessão nossos argumentos a partir das evidências levantadas em estudos empíricos realizados por pesquisadores brasileiros. Esses apresentam de forma significativa a articulação dos líderes enquanto agentes do fomento da reflexividade, da liberdade de expressão e da consideração individualizada. Os estudos escolhidos para esta análise são os de Serva (I997), Vizeu (2004) e Fraga (2000), todos desenvolvidos em organizações formais de diferentes objetivos e tamanhos, contextos organizacionais nos quais foi identificada pelos pesquisadores a predominância da orientação racional comunicativa.

O primeiro estudo a ser considerado é o de Serva (I997), que intentou verificar a racionalidade comunicativa (o autor considera a compatibilidade dessa com a racionalidade substantiva de Ramos (1989)) em três empresas baianas. Esse foi um dos primeiros estudos no Brasil que buscaram avaliar a forma como era desempenhada a prática administrativa em organizações regidas pela lógica racional-comunicativa. Para isso, Serva (I997) procurou verificar se a postura dos gestores contemplava as diretrizes emancipatórias da ação comunicativa, tais como a orientação para valores substantivos (liberdade, justiça, equidade, respeito, autonomia etc.), a preocupação com a autorrealização dos membros da organização e a reflexão sobre a organização. O autor identifica diferentes intensidades desses elementos em cada uma das três organizações pesquisadas, e, em especial, constatou a maior intensidade da racionalidade comunicativa na organização onde havia o afastamento por parte dos detentores de autoridade formal dos mecanismos burocráticos de controle e gestão, aqueles que representam a relação transacional. Para Serva (I997), o ponto central desse processo reside na opção dos gestores formais em favorecer a autonomia de decisão e escolha dos liderados, somente possível tendo em conta os valores emancipatórios fortemente presentes na comunidade organizacional. Sobre a presença desses elementos nas organizações pesquisadas, Serva (I997, p. 28) considera:

A autonomia revelou-se importante no processo de divisão do trabalho. Quanto mais autonomia se tem para assumir livremente tal ou qual atividade a desempenhar, ter viva voz no debate que leva à distribuição de tarefas, argumentar e ver os seus argumentos ser alvo de contra-argumentações autênticas, mais engajamento com o trabalho é proporcionado.

Como sugere o trecho citado, o estudo de Serva (I997) identificou que o contexto para a racionalidade comunicativa é aquele onde a autoridade formal não 
é determinante. Por conseguinte, os aspectos transacionais não são priorizados, mas sim, os mecanismos da liderança transformacional, especialmente a autonomia e a liberdade de expressão. Nesse sentido, o pesquisador conclui em seu estudo que os valores emancipatórios somente são fortalecidos quando os líderes atuam de forma sistemática, estimulando a participação e a reflexão, bem como a liberdade de expressão e a comunicação livre:

Não se muda uma realidade complexa apenas portando signos e professando valores, acima de tudo é preciso comprometer-se efetivamente com eles nas ações cotidianas. A congruência de uma organização, face a racionalidade que lhe é subjacente, não começa no produto ou tampouco na imagem ao público; começa sobretudo nos seus processos administrativos internos. Ou seja, de dentro para fora da organização, e não o contrário (SERVA, I997, p. 29).

Corroborando o estudo de Serva (1997), Vizeu (2004) e Fraga (2000) também identificaram em suas respectivas pesquisas a relação entre a ação comunicativa e a liderança transformacional. Em seu estudo sobre uma organização produtiva da cidade de Porto Alegre, Fraga identifica que um ponto central de favorecimento da ação comunicativa é a postura recíproca entre líder e liderados. Essa postura implica que os detentores de autoridade formal dispam-se de suas fontes de poder transacional e portem-se como membros da mesma comunidade organizacional. Um dos depoimentos dos funcionários da empresa investigada por Fraga (2000) revela essa postura por parte dos gestores:

Grande parte das vezes quando surge um problema, se busca a solução em conjunto [...] mesmo os Diretores ou os Encarregados não se sentem constrangidos em dizer que não sabem ou não têm a solução, a resposta para aquele problema e dizem: "vamos aprender juntos" [...] existe a liberdade de se dar idéias, sugerir alguma coisa [...] as pessoas te ouvem e a tua opinião é levada em consideração. Tu pode, através da argumentação, convencer o grupo de que a tua resposta pode ser a mais adequada para aquele problema (FRAGA, 2000, p. 84).

Esse depoimento é significativo porque é de um membro não detentor de autoridade formal, e revela que ele percebe sua capacidade de argumentar e a possibilidade de ser ouvido. Entretanto, essa postura é possível justamente porque os detentores da autoridade formal atuam diretamente para formar esse estado psicológico de participação e engajamento. Além de ter sido identificado no estudo de Fraga (2000), essa postura da gerência também foi observada na pesquisa de Vizeu (2004) sobre um hospital psiquiátrico de Curitiba. Neste 
último estudo em particular, um ponto forte de fomento da ação comunicativa identificado é a postura dos coordenadores da unidade terapêutica, que fazem questão de se inserir no grupo como um membro de iguais direitos e poder de decisão. Um dos depoimentos apresentados no estudo revela bem essa postura:

Eu não sou chefe... Eu divido com todas as pessoas dentro da minha equipe. Eu estou nessa função como representante. Eu levo notícias e trago notícias... Mas não que essa função dependa de mim. É repartido em grupo. Então eu não me sinto nem mais nem menos do que nenhum deles, eu me sinto junto com todos. Desde a servente até o paciente (VIZEU, 2004, p. 128).

Seja na organização investigada por Vizeu (2004), seja na de Fraga (2000), os mecanismos de identificação da autoridade formal são eliminados ou minimizados - na indústria, todos usam o mesmo jaleco que os operários, e no hospital, os médicos não usam a tradicional roupa branca, elementos simbólicos de manifestação da autoridade. Nesse sentido, a reciprocidade é uma fonte de legitimação da liderança, que não se opõe pelos seus mecanismos formais de controle e barganha (a liderança transacional).

Um último ponto de aproximação entre a TAC e a perspectiva da liderança transformacional consiste na construção de uma relação que permite enxergar o outro como um participante legítimo da esfera pública onde se estabelece a interação social. Para isso, a ênfase na comunicação e no diálogo orientados para o reconhecimento do outro está presente tanto na TAC quanto no modelo da liderança transformacional. Como indicaram Vizeu e Bin (2008), a ação comunicativa somente se estabelece quando há o reconhecimento do outro como um sujeito com poder de participação legítimo, e isso só ocorre quando há o reconhecimento das motivações do outro - no mínimo, quando há a intenção desse reconhecimento. Essa preocupação foi identificada tanto na pesquisa de Serva (1997) quanto nos estudos de Fraga (2000) e Vizeu (2004). Assim, o fato de o líder transformacional atuar como um apoiador dos seguidores em seus anseios, mas também como alguém preocupado em conhecer-lhes suas preocupações e a maneira com veem as coisas indica que esse modelo corresponde ao perfil psicológico que viabiliza a ação comunicativa.

\section{CONCLUSÃO}

Em nossas considerações finais, a primeira tarefa que se apresenta nessa tentativa de aproximação entre essas duas referências teóricas de natureza tão distin- 
ta é considerar os limites desse intento. Nesse sentido, devemos nos questionar: é possível pensar em um modelo de liderança permeado pela ação comunicativa?

Em resposta a esse questionamento, o primeiro obstáculo que reconhecemos diz respeito à noção de influência, que transparece como uma referência central para a abordagem de liderança transformacional. Mesmo se configurando como um modelo que visa à emancipação pela ação humana coletivamente orientada, persiste na construção teórica proposta da liderança transformacional a ideia de que a liderança é uma relação de influência, em que um influencia e outros são influenciados. O perigo dessa noção, quando se constitui a interação social à luz da perspectiva habermasiana, é o de comprometer o principal elemento de constituição de um espaço de fala livre, a reciprocidade. Nesse sentido, não se pode conceber a ação comunicativa a partir de relações de poder assimétricas. É por isso que defendemos o modelo de liderança transformacional desvinculado da ideia de autoridade formal, algo nem sempre buscado pelos adeptos dessa abordagem, tal como Bass (I985; I990) e Bennis e Nanus (I988). É por isso que reforçamos que não somente o gerente pode assumir uma perspectiva de liderança transformacional, mas também aqueles que não possuem autoridade formalmente instituída. Na verdade, esses seriam os grandes agentes da liderança transformacional, tendo em conta que a autoridade formal é um constragimento pré-linguístico para a ação comunicativa, conforme apontaram Felts (I992) e Forester (I994).

Além disso, ressaltamos a necessidade de reconhecimento mútuo, ou seja, a consideração do outro como um membro do grupo de referência ao qual pertencemos, com direitos e vontade legítimos. Como foi observado, essa postura psicológica é fundamental para o favorecimento da liderança transformacional, não sendo suficiente apenas a ruptura com os mecanismos de autoridade formal que se impõem como constrangimentos pré-linguísticos. Isso foi observado no estudo de Vizeu e Bin (2008) sobre o conselho consultivo da presidência da República, que, mesmo se estabelecendo sob condições de funcionamento favoráveis à democracia deliberativa, não foi capaz de estabelecer o reconhecimento mútuo necessário para a reciprocidade e a orientação para o entendimento.

Nesse sentido, o desafio para o estabelecimento da liderança transformacional nas organizações modernas é justamente o fato de esses espaços sociais serem fortemente condicionados para a postura psicológica de negação de valores existenciais e de grupo, tendo em vista que, em nossa sociedade, a orientação técnico-econômica das relações de mercado capitalista prevalece como medida principal. Como afirma Ramos (I989), mesmo nas relações sociais não econômicas, a lógica de mercado se faz mais forte, suplantando outras referências da conduta humana. Ser pragmático é a grande medida da administração nessas 
organizações, e, por isso, não se estabelece um contexto favorável para a integração transformadora. Os valores existenciais - a base da liderança transformadora - são obscurecidos pelo valor do dinheiro e do poder burocrático.

É por esse motivo que defendemos no presente artigo que o líder somente será um agente facilitador da ação comunicativa na medida em que se despir dos artifícios transacionais que, no âmbito da burocracia, são os mecanismos de controle atribuídos ao cargo formal. Isso não significa dizer que somente não detentores de autoridade formal poderão ser líderes transformacionais; apenas consideramos que administradores e supervisores formalmente instituídos não poderão basear sua autoridade nos mecanismos formais. Além disso, como foi observado nos casos estudados por Fraga (2000) e Vizeu (2004), é proveitoso para a facilitação da liderança transformacional que os detentores de autoridade formal evitem os indicadores dessa autoridade, quando possível. Na verdade, isso corrobora nosso entendimento de que a liderança transformacional é fortemente favorecida pelo contexto no qual ela se estabelece, algo defendido por Burns (I978) em seu livro seminal, mas que foi ofuscado pela tradição de pesquisas comportamentalistas de Bass (1985; I990) e seus seguidores. Recuperar este sentido original foi, de certo modo, uma das intenções do presente artigo.

\section{AN APPROACH BETWEEN THE TRANSFORMATIONAL LEADERSHIP AND THE THEORY OF COMMUNICATIVE ACTION}

\section{ABSTRACT}

Since the seminal Burns' work about transformational leadership, many other authors have argued that leaders are successful if they don't behave like managers. As far as being an argument without theoretical basis, it is argued that the transformational leadership model can be considered from the point of view of more-complex theoretical social approaches, like for instance the Habermas' theory of communicative action. This is the proposal of this paper, that, considering the dichotomy between the strategic action and the communicative action, analyzed the ontological foundations for distinguishing between managers and transformational leaders. In these lines, it is argued that the Theory of Communicative Action provides a critical analysis of the transformational leadership, since it permits a better comprehension of some of its elements, while it questions others, providing a less naive understanding about the leadership phenomenon, such that presented by the managerial view in the leadership studies. 
One of these contributions is the construal of the transformational leadership as a phenomenon contextualized by the freedom of the speech, propitiating the communicative action through organizational mechanisms that are free of communicative interaction constrains, allowing reciprocity among leadership agents.

\section{KEYWORKS}

Transformational leadership; Transational leadership; Leader-manager dichotomy; Communicative action; Instrumental rationality.

\section{UNA APROXIMACIÓN ENTRE EL LIDERAZGO TRANSFORMACIONAL Y LA TEORÍA DE LA ACCIÓN COMUNICATIVA}

\section{RESUMEN}

Desde el trabajo seminal de Burns (I978) sobre el liderazgo transformacional, muchos autores defienden que líderes son bien sucedidos en la medida en que dejan de ser gerentes. Lejos de representar a penas un argumento vacío de fundamentación teórica, defendemos que el modelo de liderazgo transformacional puede ser considerado a partir de teorías sociales más complejas, como por ejemplo, la Teoría de la Acción Comunicativa de Habermas. Esta es la propuesta de este trabajo, que, considerando la dicotomía entre la acción estratégica (orientada al éxito) y la acción comunicativa (orientada hacia el entendimiento intersubjetivo), observó los fundamentos ontológicos para la diferenciación hecha entre el gerente y el líder transformacional. En este sentido, reconocemos que la Teoría de la Acción Comunicativa provee análisis crítica del liderazgo transformacional, pues permite una mejor comprensión de algunos de sus elementos, al mismo tiempo en que cuestiona otros, vislumbrando un entendimiento sobre el fenómeno del liderazgo menos ingenuo, tal cual aquél presentado por la visión gerencialista en los estudios del liderazgo. Una de estas contribuciones es la concepción del liderazgo transformacional como un fenómeno contextualizado por la libertad de habla propicia a la acción comunicativa, tal cual estudios empíricos sobre este modelo de acción han procurado apuntar, donde los mecanismos de organización que condicionan la interacción social son libres de coacción a la interacción comunicativa plena, permitiendo la reciprocidad entre los agentes del liderazgo. 


\section{PALABRAS CLAVE}

\section{Liderazgo transformacional; Liderazgo transaccional; Dicotomía líder-gerente; Acción comunicativa; Racionalidad instrumental.}

\section{REFERÊNCIAS}

ALVESSON, M.; DEETZ, S. Teoria crítica e abordagens pós-modernas para estudos organizacionais. In: CLEGG, S. R.; HARDY, C.; NORD, W. R. (Org.). Handbook de estudos organizacionais: modelos de análise e novas questões em estudos organizacionais. São Paulo: Atlas, I999. v. I, p. 227-27I.

ARAGÃO, L. M. de C. Razão comunicativa e teoria social crítica em Jürgen Habermas. 2. ed. Rio de Janeiro: Tempo Brasileiro, I997.

AVOLIO, B. J.; BASS, B. M. The full range of leadership development: basic and advanced manuals. Binghamton: Bass, Avolio \& Associates, I99I.

BAILEY, J.; AXELROD, R. H. Leadership lessons from Mount Rushmore: an interview with James MacGregor Burns. Leadership Quarterly, Oxford, v. I2, p. II3-I27, Spring, Jan./Mar. 200 I.

BARBUTO JR., J. E. Taking the charisma out of transformational leadership. Journal of Social Behavior and Personality, Novato, v. I2, n. 3, p. 689-697, Apr./Jun. I997.

BASS, B. M. Leadership and performance beyond expectations. New York: Free Press, I985.

From transactional to transformational leadership: learning to share the vision. Organizational Dynamics, Oxford, v. I8, n. 3, p. I9-3I, Oct./Dec. I990.

Two decades of research and development in transformational leadership. European Journal of Work and Organizational Psychology, Oxford, v. 8, n. I, p. 9-32, Jan./Mar. I999a.

Ethics, character, and authentic transformational leadership behavior. Leadership Quarterly, Oxford, v. IO, n. 2, p. I8I-2I8, Apr./Jun. I999b.

BASS, B. M.; AVOLIO, B. J. Developing transformational leadership: I992 and beyond. Journal of European industrial Training, Bingley, issue 5, v. I4, p. 2I-27, Sept./Oct. I990.

BENNIS, W. A formação do líder. São Paulo: Atlas, ı996.

BENNIS, W.; NANUS, B. Líderes: estratégias para assumir a verdadeira liderança. São Paulo: Harbra, I988.

BERGAMINI, C. W. Liderança: uma revisão histórica. In: Liderança: administração do sentido. São Paulo: Atlas, I994. p. 23-74.

BRAVERMAN, H. Trabalho e capital monopolista. 3. ed. Rio de Janeiro: Zahar, I98I.

BURNS, J. M. Leadership. New York: Harper and Row, 1978.

CHANDLER, A. D. The Visible Hand: the Managerial Revolution in American Business. Cambridge: Harvard University Press, I977.

DRUCKER, P. Uma era de descontinuidade: orientações para uma sociedade em mudança. Rio de Janeiro: Zahar, ı970.

As novas realidades: no governo e na política, na economia e nas empresas, na sociedade e na visão do mundo. São Paulo: Pioneira, I990. 
DVIR, T. et al. Impact of transformational leadership on follower development and performance: a field experiment. Academy of Management Journal, New York, v. 45, n. 4, p. 735-744, Jul./Aug. 2002. FELTS, A. A. Organizational communication. Administration \& Society, London, v. 23, n. 4, p. 495517, Feb. I992.

FORESTER, J. Teoria crítica e análise organizacional. Plural, São Paulo, v. I, n. I, p. I3I-I48, jan./ jun. I994.

FRAGA, M. L. A empresa produtiva e a racionalidade substantiva. 2000. Dissertação (Mestrado em Administração)-Universidade Federal do Rio Grande do Sul, Porto Alegre, 2000.

GARCIA, R. A Base de uma administração auto-determinada: O diagnóstico emancipador. Revista Administração Empresas, São Paulo, v. 20, n 2, p. 7-I7, abr./jun. I980.

HABERMAS, J. Conhecimento e interesse. In: Textos escolhidos. São Paulo: Abril Cultural, I975. p. 29I-302. (Coleção os Pensadores).

. Teoría de la acción comunicativa. Tomo I: racionalidad de la acción y racionalización social. Madrid: Taurus, I987.

Teoría de la acción comunicativa: complementos e estudios previos. Madrid: Cátedra, I989a. Para o uso pragmático, ético e moral da razão prática. Estudos Avançados, São Paulo, v. 3, n. 7, p. 4-I9, set./dez. I989b.

Pensamento pós-metafísico: estudos filosóficos. Rio de Janeiro: Tempo Brasileiro, I990.

RAMOS, A. G. A nova ciência das organizações: uma reconceituação da riqueza das nações. 2. ed. Rio de Janeiro: FGV, I989.

SERVA, M. A racionalidade substantiva demonstrada na prática administrativa. Revista de Administração de Empresas, São Paulo, v. 37, n. 2, p.I8-30, abr./jun. I997.

SHAMIR, B. The charismatic relationship: alternative explanations and predictions. Leadership Quarterly, Oxford, v. 2, n. 2, p. 8I-Io4, Apr./Jun. I99I.

VIZEU, F. Organizações burocratizadas rumo à razão comunicativa: o caso de uma instituição psiquiátrica. 2004. Dissertação (Mestrado em Administração)-Universidade Federal do Paraná, Curitiba, 2004 .

Ação Comunicativa e Estudos Organizacionais. Revista de Administração de Empresas, São Paulo, v. 45, p. IO-2I, out./dez. 2005.

VIZEU, F.; BIN, D. Democracia deliberativa: leitura crítica do caso CDES à luz da teoria do discurso. Revista Brasileira de Administração Pública, Rio de Janeiro, v. 42, p. 83-Io8, jan./mar. 2008.

WEBER, M. Ensaios de sociologia. 3. ed. Rio de Janeiro: Zahar, I974. 